\title{
On the inefficiency of Bitcoin
}

DOI:

10.1016/j.econlet.2016.10.033

\section{Document Version}

Accepted author manuscript

Link to publication record in Manchester Research Explorer

\section{Citation for published version (APA):}

Nadarajah, S. (2017). On the inefficiency of Bitcoin. Economics Letters, 150.

https://doi.org/10.1016/j.econlet.2016.10.033

\section{Published in:}

Economics Letters

\section{Citing this paper}

Please note that where the full-text provided on Manchester Research Explorer is the Author Accepted Manuscript or Proof version this may differ from the final Published version. If citing, it is advised that you check and use the publisher's definitive version.

\section{General rights}

Copyright and moral rights for the publications made accessible in the Research Explorer are retained by the authors and/or other copyright owners and it is a condition of accessing publications that users recognise and abide by the legal requirements associated with these rights.

\section{Takedown policy}

If you believe that this document breaches copyright please refer to the University of Manchester's Takedown Procedures [http://man.ac.uk/04Y6Bo] or contact uml.scholarlycommunications@manchester.ac.uk providing relevant details, so we can investigate your claim.

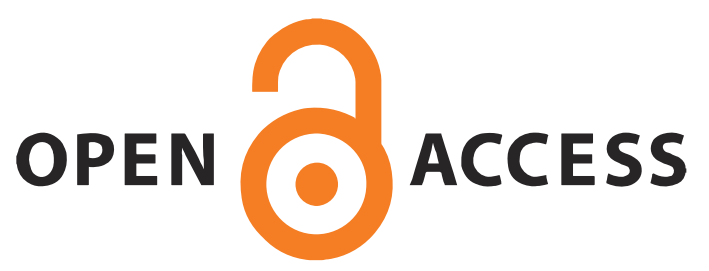




\title{
On the inefficiency of Bitcoin
}

\author{
by \\ Saralees Nadarajah and Jeffrey Chu \\ School of Mathematics, University of Manchester, Manchester M13 9PL, UK
}

\begin{abstract}
Urquhart (2016) investigated the market efficiency of Bitcoin by means of five different tests on Bitcoin returns. It was concluded that the Bitcoin returns do not satisfy the efficient market hypothesis. We show here that a simple power transformation of the Bitcoin returns do satisfy the hypothesis through the use of eight different tests. The transformation used does not lead to any loss of information.
\end{abstract}

Keywords: Independence; Random walk hypothesis; Serial correlation

\section{Introduction}

Introduced and first documented by Satoshi Nakamoto in 2009, Bitcoin is a form of cryptocurrency - an "electronic payment system based on cryptographic proof" (Nakamoto, 2009), instead of traditional trust. Several authors have modeled Bitcoin data in recent years. Garcia et al. (2014) studied the links between social signals and Bitcoin price through a social feedback cycle. Kristoufek (2013) studied the relationship between digital currencies, such as Bitcoin, and search queries through Google Trends and Wikipedia. Moore and Christin (2013) provided an empirical analysis of Bitcoin-Exchange Risk. Glaser et al. (2014)'s analysis looked into whether Bitcoin intra-network transaction and on-exchange trading volumes are linked, and also tries to determine if Bitcoin can be classed as an asset or a currency. Hencic and Gourieroux (2014) modeled and predicted the Bitcoin/USD exchange rate through the application of a non-causal autoregressive model. Kondor et al. (2014) looked at the structure and evolution of the Bitcoin transaction network. The study of Sapuric and Kokkinaki (2014) measured volatility of the exchange rate of Bitcoin against six major currencies. Using a known technique that is robust in detecting bubbles, Cheung et al. (2015) investigated the existence of bubbles in the Bitcoin market. Through wavelet coherence analysis, Kristoufek (2015) examined Bitcoin price formation and the main drivers of price.

One of the fundamental principals for modeling of financial data is the efficient market hypothesis due to Fama (1970). There are three forms of this hypothesis. The one most commonly used is the weak form of the efficient market hypothesis. The weak form implies that investors cannot use past information to predict future returns.

Urquhart (2016) was the first to test the weak form for Bitcoin data. He used five different tests and concluded that Bitcoin returns are market inefficient. We follow up Urquhart (2016)'s work here. We test the same hypothesis not on the Bitcoin returns but an odd integer power of the Bitcoin returns, note that powering to an odd integer does not lead to any loss of information. Our results show that the transformed Bitcoin returns are actually market efficient. So, after all, everything is not so negative about Bitcoin.

The contents of this note are organized as follows. The Bitcoin data used and a brief descriptive analysis are presented in Section 2. The tests performed and their results are discussed in Section 
3. Finally, some conclusions are noted in Section 4.

\section{Data}

The data are as in Urquhart (2016), that is, daily closing prices for Bitcoin in USD from the 1st of August 2010 to 31st of July 2016. A plot of the data is shown in Figure 1 in Urquhart (2016). As in Urquhart (2016), we consider data from three periods: the full period from the 1st of August 2010 to 31st of July 2016; the subsample period from the 1st of August 2010 to 31st of July 2013; the subsample period from the 1st of August 2013 to 31st of July 2016.

We computed the Bitcoin returns as

$$
R_{t}=100 \cdot \ln \left(\frac{P_{t}}{P_{t-1}}\right)
$$

where $P_{t}$ and $P_{t-1}$ denote the closing prices on days $t$ and $t-1$, respectively.

To investigate the efficient market hypothesis, we propose dealing with $R_{t}^{m}$ where $m$ is an odd integer. This way no information is lost. If $R_{t}$ is negative $R_{t}^{m}$ will still be negative. If $R_{t}$ is positive $R_{t}^{m}$ will still be positive. If $R_{t}$ is zero $R_{t}^{m}$ will still be zero.

\begin{tabular}{cccc}
\hline Statistic & $1 / 8 / 2010-31 / 7 / 2016$ & $1 / 8 / 2010-31 / 7 / 2013$ & $1 / 8 / 2013-31 / 7 / 2016$ \\
\hline $\mathrm{N}$ & 2191 & 1095 & 1095 \\
Minimum & $-5.706 \times 10^{-4}$ & $-5.706 \times 10^{-4}$ & $-2,102 \times 10^{-8}$ \\
Q1 & 0.000 & 0.000 & 0.000 \\
Median & 0.000 & 0.000 & 0.000 \\
Mean & $-2.406 \times 10^{-7}$ & $-4.829 \times 10^{-7}$ & $1.497 \times 10^{-9}$ \\
Q3 & 0.000 & 0.000 & 0.000 \\
Maximum & $4.735 \times 10^{-5}$ & $4.735 \times 10^{-5}$ & $1.592 \times 10^{-6}$ \\
SD & $1.225 \times 10^{-5}$ & $1.733 \times 10^{-5}$ & $4.816 \times 10^{-8}$ \\
CV & -50.906 & -35.878 & 32.181 \\
Skewness & -46.084 & -32.556 & 32.927 \\
Kurtosis & 2147.745 & 1072.416 & 1087.655 \\
\hline
\end{tabular}

Table 1: Some summary statistics.

We choose $m=17$, although smaller values could also be chosen. The following descriptive statistics of $R_{t}^{m}$ are shown in Table 1: number of observations, minimum, first quartile, median, mean, third quartile, maximum, standard deviation, coefficient of variation, skewness and kurtosis.

The mean and median of the Bitcoin returns are approximately zero. The variability appears largest for the first subsample period and smallest for the second subsample period. The distribution of the Bitcoin returns are extremely skewed for all three periods. The full and the first subsample periods are negatively skewed. The second subsample period is positively skewed. The distribution of the Bitcoin returns are extremely peaked for all three periods. The degree of peakedness appears largest for the full period and smallest for the first subsample period. 


\section{Tests}

We now test the efficient market hypothesis using various tests, including the ones used in Urquhart (2016).

Firstly, we performed the Ljung-Box (Ljung and Box, 1978) test for no autocorrelation. The $p$-values are plotted in Figure 1 for lags from 1 to 10 . There is no evidence against the hypothesis of no autocorrelation.
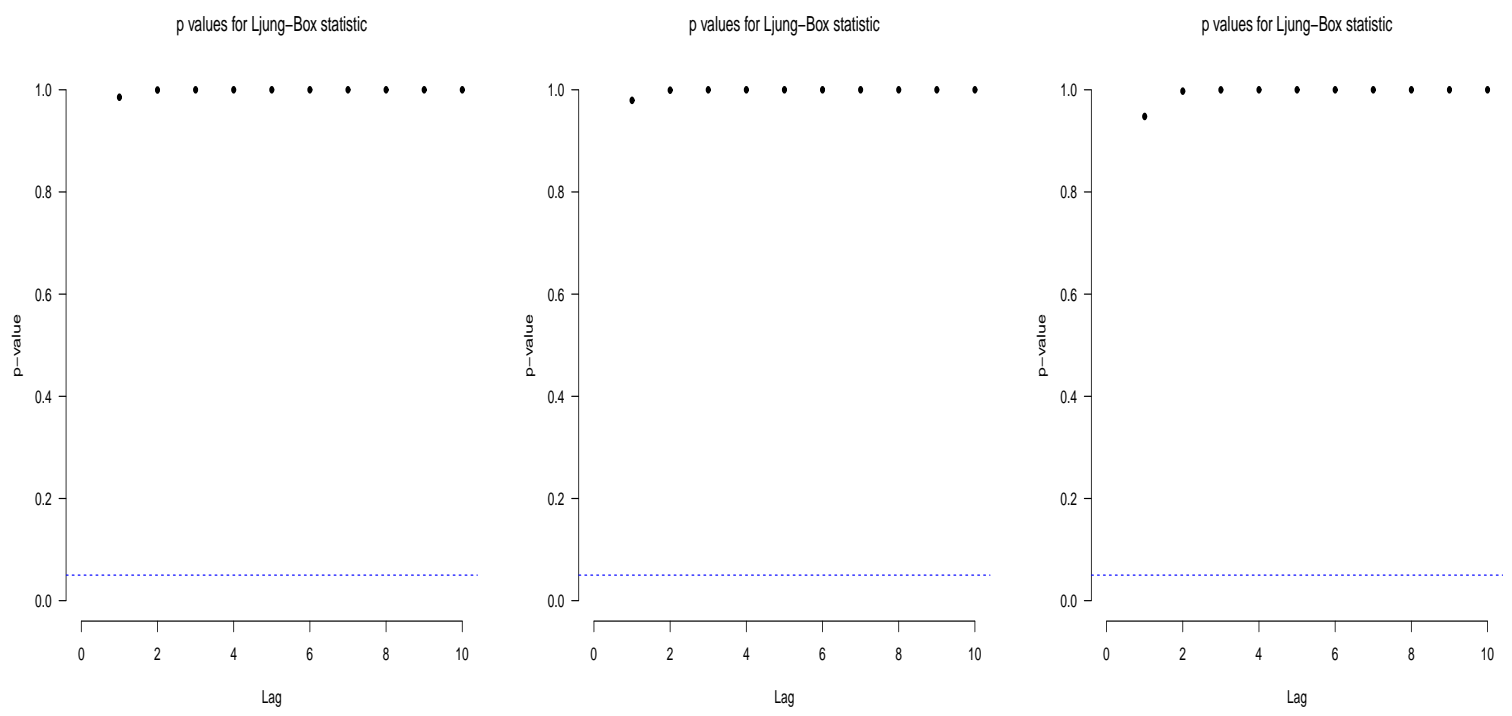

Figure 1: $p$-values of the Ljung-Box test versus lag: full period (left), first subsample period (middle) and second subsample period (right).

Secondly, we performed the runs test (Wald and Wolowitz, 1940) for independence of the returns. The $p$-values for the full, first subsample and second subsample periods were $0.019,0.489$ and 0.809 , respectively. Hence, there is no evidence against the hypothesis of independence for the two subsample periods. The evidence against for the full period is not that strong.

Thirdly, we performed the Bartel's test (Bartel, 1982) also to test independence of the returns. The $p$-values for the full, first subsample and second subsample periods were $0.009,0.011$ and 0.388 , respectively. Hence, there is no evidence against the hypothesis of independence for the second of the two subsample periods. The evidence against for the full period appears strong.

Fourthly, we performed the wild-bootstrapped automatic variance ratio test (Kim, 2009) to check whether the random walk hypothesis holds for the returns. The $p$-values for the full, first subsample and second subsample periods were $0.475,0.465$ and 0.5 , respectively. Hence, there is no evidence against the random walk hypothesis.

Furthermore, plots of the variance ratios versus holding period are shown in Figure 2 for the full, first subsample and second subsample periods. The variance ratios are within the 95 percent confidence bands. This gives further evidence to support the random walk hypothesis. 

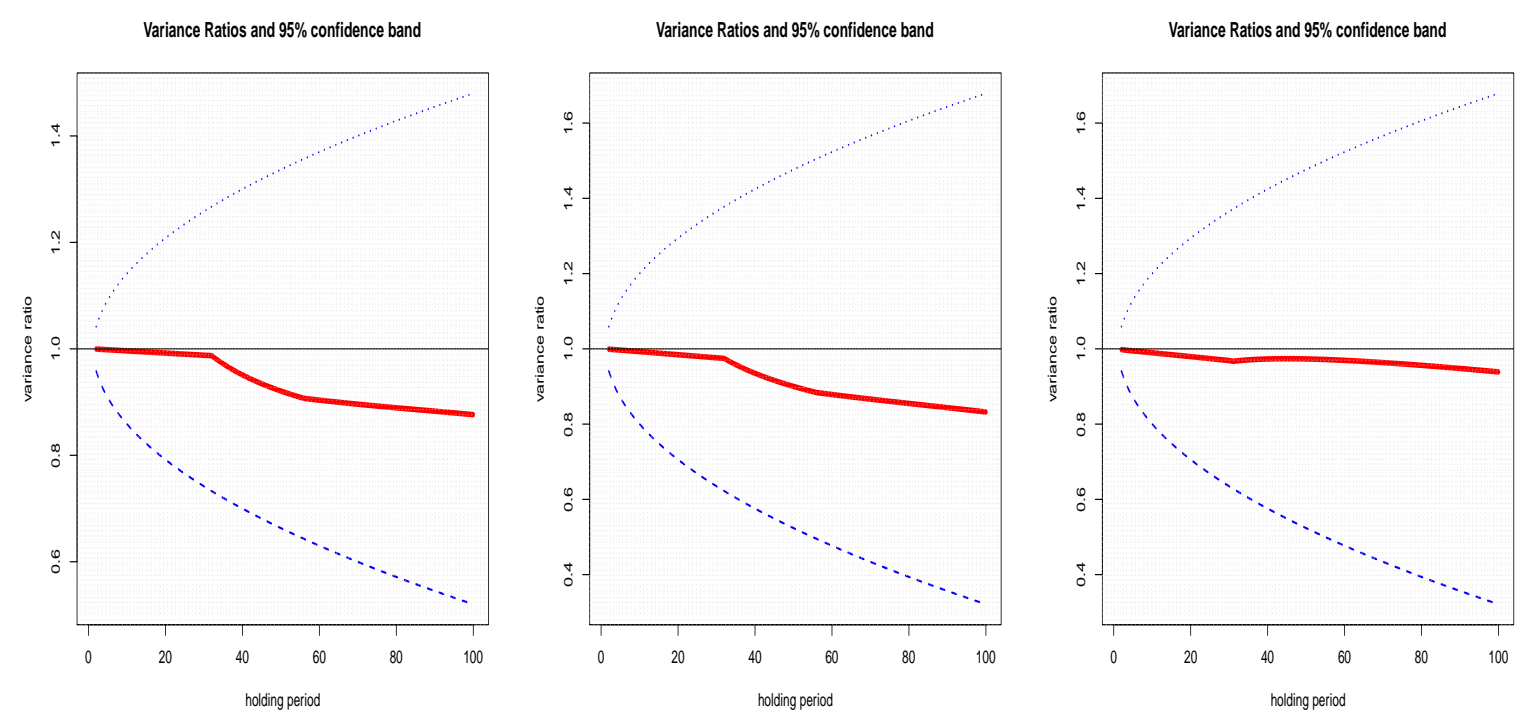

Figure 2: Variance ratio statistic versus holding period: full period (left), first subsample period (middle) and second subsample period (right).

Fifthly, we performed the spectral shape tests (Durlauf, 1991; Choi, 1999) also to test if the random walk hypothesis holds for the returns. The $p$-values based on the Anderson-Darling statistic for the full, first subsample and second subsample periods were 1, 1 and 1 , respectively. The $p$ values based on the Cramer-von Mises statistic for the full, first subsample and second subsample periods were 1, 1 and 1, respectively. Hence, yet again there is no evidence against the random walk hypothesis.

Sixthly, we performed the BDS test (Brock et al., 1996) that the returns are independently and identically distributed. The $p$-values for the full period were $0.932,0.908,0.932,0.908,0.932,0.907$, 0.966 and 0.954 . The $p$-values for the first subsample period were $0.903,0.870,0.903,0.870,0.952$, $0.935,0.952$ and 0.935 . The $p$-values for the second subsample period were $0.952,0.935,0.952$, $0.935,0.952,0.935,0.976$ and 0.967 . Hence, there is no evidence against the hypothesis that the returns are independently and identically distributed.

Seventhly, we performed the robustified portmanteau test (Escanciano and Lobato, 2009) for no serial correlation. The $p$-values for the full, first subsample and second subsample periods were $0.513,0.513$ and 0.258 , respectively. Hence, there is no evidence against no serial correlation.

Finally, we performed the generalized spectral test (Escanciano and Lobato, 2006) to check whether the martingale difference hypothesis holds for the returns. The $p$-values for the full, first subsample and second subsample periods were $0.287,0.223$ and 0.250 , respectively. Hence, there is no evidence against the martingale difference hypothesis.

\section{Conclusions}

The tests in Section 3 have shown that an odd integer power of Bitcoin returns are largely weakly efficient over the full period as well as over the two subsample periods. We have used eight different tests: Ljung-Box test for no autocorrelation; runs test for independence; Bartel's test for 
independence; wild-bootstrapped automatic variance ratio test for the random walk hypothesis; spectral shape tests for the random walk hypothesis; BDS test that the returns are independently and identically distributed; robustified portmanteau test for no serial correlation; the generalized spectral test for the martingale difference hypothesis. Most of the tests showed no evidence against the null hypothesis. The only tests that gave evidence against the null hypothesis were the tests for independence.

Urquhart (2016) applied the following tests to check weak efficiency of Bitcoin returns: LjungBox test for no autocorrelation; runs test for independence; Bartel's test for independence; wildbootstrapped automatic variance ratio test for the random walk hypothesis; BDS test that the returns are independently and identically distributed. According to his results, the Ljung-Box and wild-bootstrapped automatic variance ratio tests supported the weakly efficient hypothesis for the second of the two subsample periods. The weakly efficient hypothesis was not supported by other tests or for other periods.

As explained in Section 2, powering of Bitcoin returns to odd integers does not lead to any loss of information. Powering to even integers will lead to loss of information because the transformed values will always be non-negative (returns can be negative). Powering to real numbers is not strictly possible because real powers of negative returns are mathematically undefined. So, the only power transformation that can be applied to Bitcoin returns without loss of information is the odd integer power transformation. For illustration, we have taken the odd integer to be equal to 17, but similar results held for other odd integers smaller or larger than 17. The transformed data obtained this way is less variable, more peaked, more skewed, less serially correlated, less autocorrelated, more like a random walk and more independently and identically distributed compared to the original returns. Models can be fitted to the transformed data and forecasts made. The forecasts can then be transformed back to the original scale.

\section{Acknowledgement}

The authors would like to thank the Editor and the referee for careful reading and comments which improved the paper.

\section{References}

[1] Bartels, R. (1982). The rank version of von Neumann's ratio test for randomness. Journal of the American Statistical Association, 77, 40-46.

[2] Brock, W. A., Dechert, W. D., Schieinkman, J. A. and LeBaron, B. (1996). A test for independence based on the correlation dimension. Econometric Reviews, 15, 197-235.

[3] Cheung, A., Su, J. J. and Roca, E. (2015). Crypto-currency bubbles: An application of the Phillips-Shi-Yu (2013) methodology on Mt. Gox Bitcoin prices. Applied Economics, 47, 2348-2358.

[4] Choi, I. (1999). Testing the random walk hypothesis for real exchange rates. Journal of Applied Econometrics, 14, 293-308.

[5] Durlauf, S. N. (1991). Spectral based testing of the martingale hypothesis. Journal of Econometrics, 50, 355-376. 
[6] Escanciano, J. C. and Velasco, C. (2006). Generalized spectral tests for the martingale difference hypothesis. Journal of Econometrics, 134, 151-185.

[7] Escanciano, J. C. and Lobato, I. N. (2009). An automatic portmanteau test for serial correlation. Journal of Econometrics, 151, 140-149.

[8] Fama, E. F. (1970). Efficient capital markets: A review of theory and empirical work. Journal of Finance, 25, 383-417.

[9] Garcia, D., Tessone, C. J., Mavrodiev, P. and Perony, N. (2014). The digital traces of bubbles: Feedback cycles between socio-economic signals in the Bitcoin economy. Journal of the Royal Society Interface, 11, 20140623

[10] Glaser, F., Zimmermann, K., Haferkorn, M., Weber, M. C. and Siering, M. (2014). Bitcoin Asset or currency? Revealing users' hidden intentions. In: Proceedings of the Twenty Second European Conference on Information Systems, Recanati Business School, Tel Aviv University, Tel Aviv.

[11] Hencic, A. and Gourieroux, C. (2014). Noncausal autoregressive model in application to Bitcoin/USD exchange rate. In: Proceedings of the 7th Financial Risks International Forum, Paris, France.

[12] Kim, J. H. (2009). Automatic variance ratio test under conditional heteroskedasticity. Finance Research Letters, 3, 179-185.

[13] Kondor, D., Posfai, M., Csabai, I. and Vattay, G. (2014). Do the rich get richer? An empirical analysis of the Bitcoin transaction network. PLoS ONE, 9, e86197

[14] Kristoufek, L. (2013). BitCoin meets Google Trends and Wikipedia: Quantifying the relationship between phenomena of the Internet era. Scientific Reports, 3, 3415.

[15] Kristoufek, L. (2015). What are the main drivers of the Bitcoin price? Evidence from wavelet coherence analysis. PLoS ONE, 10, e0123929

[16] Ljung, G. M. and Box, G. E. P. (1978). On a measure of the lack of fit in time series models. Biometrika, 65, 297-303.

[17] Moore, T. and Christin, N. (2013). Beware the middleman: Empirical analysis of Bitcoinexchange risk. Financial cryptography and data security. Lecture Notes in Computer Science. 7859, 25-33.

[18] Nakamoto, S. (2009). Bitcoin: A peer-to-peer electronic cash system. https://Bitcoin.org/Bitcoin.pdf

[19] Sapuric, S. and Kokkinaki, A. (2014). Bitcoin is volatile! Isn't that right? In: Business Information Systems Workshops, Lecture Notes in Business Information Processing, pp. 255265.

[20] Urquhart, A. (2016). The inefficiency of Bitcoin. Economics Letters, 148, 80-82.

[21] Wald, A. and Wolfowtiz, J. (1940). On a test whether two samples are form the same population. Annals of Mathematical Statistics, 11, 147-162. 